\title{
Association between Body Image Dissatisfaction and Goals for Physical Activity Practice in Fitness Center
}

\author{
Cristina Bonoto Vieira Da Cunha1, Ingi Petitemberte Klain ${ }^{2 *}$, Airton José Rombaldi², \\ José Carlos Leitão ${ }^{1}$ \\ ${ }^{1}$ University of Trás-os-Montes and Alto Douro (UTAD), Vila Real, Portugal \\ ${ }^{2}$ Federal University of Pelotas (UFPel), Pelotas, Rio Grande do Sul, Brasil \\ Email: ^Ingiklain@yahoo.com.br
}

How to cite this paper: Da Cunha, C.B.V., Klain, I.P., Rombaldi, A.J. and Leitão, J.C. (2018) Association between Body Image Dissatisfaction and Goals for Physical Activity Practice in Fitness Center. Open Access Library Journal, 5: e4621.

https://doi.org/10.4236/oalib.1104621

Received: April 25, 2018

Accepted: May 20, 2018

Published: May 23, 2018

Copyright $\odot 2018$ by authors and Open Access Library Inc.

This work is licensed under the Creative Commons Attribution International License (CC BY 4.0).

http://creativecommons.org/licenses/by/4.0/

\section{Open Access}

\begin{abstract}
Verifying the association between body image dissatisfaction and goals to the physical activity practice. The sample consisted of 299 goers of fitness center, of both genders, with ages between 16 and 50 years old. Information about gender, age, educational level, socioeconomic level and goals for the physical activity practice were collected using a previously tests questionnaire. Regarding the goals, the participants should identify if the motivation for the practice was related to aspects health, aesthetic or social relationships aspects, choosing yes or no. The body image was determined using the set of silhouettes and to verifying the body image dissatisfaction we considered the difference between the current silhouette and the ideal silhouette pointed out by the individuals. Numerical variables were expressed as mean \pm standard deviation and categorical variables as absolute and relative frequency. Pearson's chi-square test was used to verify the associations among goals to the practice, gender, and age group. Analysis of variance was used to verify the associations between the goals to the practice and the body image dissatisfaction. There was a low statistically significant correlation between body mass index and body image dissatisfaction $\left(\mathrm{r}_{s} 0.29-p<0.001\right)$. The proportion of women $(69 \%)$ who practiced physical activity with aesthetics goals was higher than that of men (31\%). In addition, $92 \%$ of the sample showed body image dissatisfaction. Regarding the goals to the physical activity practice, men aimed more muscular body while the women wished more lean body. Men and women have different perceptions regarding body image.
\end{abstract}

\section{Subject Areas}

Kinesiology 


\section{Keywords}

Physical Activity, Physical Appearance, Fitness Center, Motivation

\section{Introduction}

According to Alvarenga et al. [1], the corporal aesthetic appears as a value of extreme importance in our society. Considering these aesthetic standards, the sport and the physical activity play an important role in the construction and maintenance of this image. Damasceno et al. [2] confirm that the ideal body image (BI) can be constructed in several ways, including through physical activity, which is why the reason for fitness centers are the places where such a project can be developed.

McPherson \& Turnbull [3] observed that the concepts of BI are multiple. However, in general, this is understood as the image we have in our mind regarding the size, shape and appearance of our body. So, it is emphasized that the way in which the person perceives himself is more decisive in the body image dissatisfaction (BID) than the weight and the body mass index (BMI).

It should be noted that, in many cases the BID lead to the adoption of harmful behaviors in order to fit the idealized beauty model, but it is often far from healthy [1]. Thus, previous studies have verified the perception of BI for specific populations; especially for those suffering from eating disorders, but this type of observation is recent in eutrophic subjects free of such dysfunctions. Additionally, there are few studies [1] [4] sought to verify if a negative BI could decrease the motivation to practice physical activities or increase the engagement in exercise programs.

Thus, this article analyzes if the degree of BID serves to motivate individuals to increase the level of physical activity, or, on the contrary, if the dissatisfaction acts as an obstacle to the practice. Therefore, the objective was to evaluate the association between BID and the goals for the physical activity practice.

\section{Methodology}

A cross-sectional study was conducted in the present research, 299 goers of eight fitness centers, of both genders, were randomly recruited. A pilot study was conducted at one of the fitness centers to verify if the issues were understandable and whether there was some need for changes to the instrument.

The applied methodology was approved by the Committee of Ethics in Research with human beings, under the protocol n. 261-2/2009 and the data were collected after the subjects signed the Free and Informed Consent Term. Regarding individuals with less than 18 years old, their parents or guardians have signed and authorizing the participation in the study.

The study included individuals aged between 16 and 50 years old, excluding those with special needs-physical or neurological-illiterate and pregnant. In 
order to collect data regarding sex, age, educational level, socioeconomic level and goals related to physical activity practice, a previously tested questionnaire was used.

The variable age was categorized into five groups: 16 to 20 years old; 21 to 30 years old; 31 to 40 years old and 41 to 50 years old; More than 50 years old. The categories of the educational level variable were: complete elementary education; complete high school; incomplete higher education; higher education; Postgraduate LatoSensu; Postgraduate StrictoSensu. The socioeconomic level expressed income in five categories: A (the highest); B; C; D and $\mathrm{E}$ (the lowest). In relation to the calculation of BMI, the formula weight $(\mathrm{kg}) /$ height $(\mathrm{m})$ [2] is widely and internationally used.

In relation to the goals, the participants should identify whether the motivation for the physical activity practice was related to health, aesthetic or social relations aspects. In addition, they should say yes (1) or no (0) for each objective. Subsequently, the relationship between these objectives and the BID was established.

In order to measure the BI, the set of silhouettes adapted by Damasceno [2] was used, which presents different figures of each gender, being on the right the most muscular, in the center, the leanest and on the left, the most obese (Figure 1).

With this type of instrument, it is possible to study the desire to change the body in terms of fat and muscles, which allows individuals to see the image they really want to achieve. The set of silhouettes was shown to the individuals, accompanied by the question: "What silhouette represents your current physical appearance (CS) and what silhouette would you like to have (IS)?” In order to guarantee the reliability of the answer, the interviewer declined his opinion on the choice of silhouettes. Afterwards, the difference between CS and IS was used.

Statistical analysis was performed using the SPSS 22.0 statistical package for Windows. Numerical variables were expressed as mean \pm standard deviation and categorical variables as absolute and relative frequency. The associations between the goals for the physical activity practice, gender and age group were for the physical activity practice and BID were verified using analysis of variance

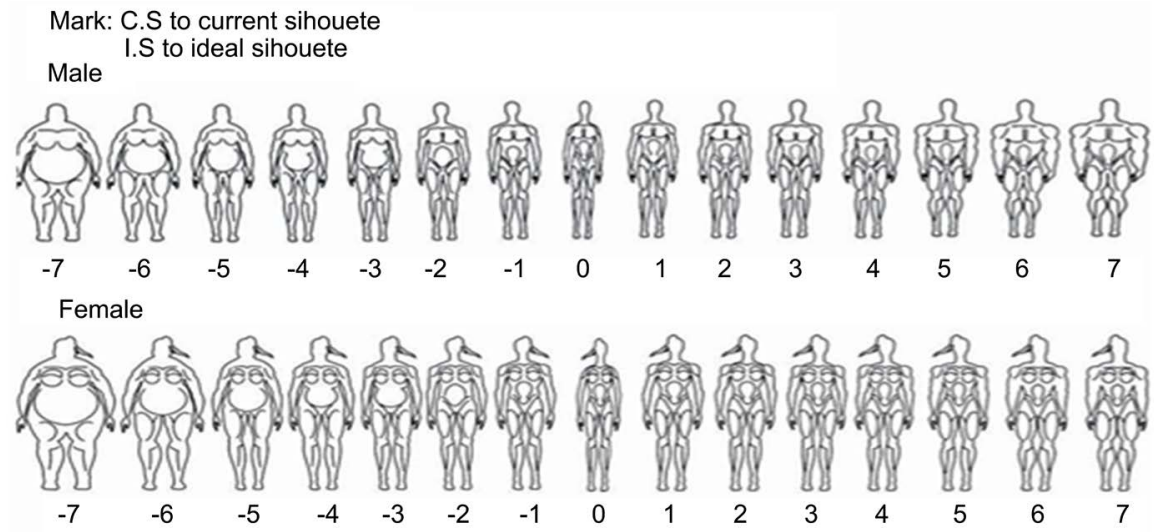

Figure 1. Set of silhouettes used to measure body image. Source: Damasceno2. 
performed using the Pearson chi-square test. The associations between the goals with a classification criterion. A probability value $p<0.05$ was considered statistically significant.

\section{Results}

The most of the individuals in the sample were female (62.2\%), between 16 and 30 years old (63.2\%), and belonged to socioeconomic level A (54.1\%). Regarding the level of education, incomplete or complete higher education were de more prevalent categories $(46.8 \%)$ (Table 1$)$.

The median BID observed was $2(2-4)$ points, (these scores refer to the measure of median variability). Figure 2 describes the distribution of BID in the study sample.

There was no statistically significant difference between men and women regarding BID ( $3.1 \pm 2.3$ vs $2.9 \pm 2.0, \mathrm{~F}=0.59, p=0.442)$ or social relations $(15.7 \pm$ 2.0 vs. $15.8 \pm 2.0, \mathrm{~F}=0.05, p=0.828)$.

Table 1. Sociodemographic characteristics of the sample $(n=299)$.

\begin{tabular}{|c|c|}
\hline Variables & n (\%) \\
\hline \multicolumn{2}{|l|}{ Gender } \\
\hline Female & $186(62.2 \%)$ \\
\hline Male & $113(37.8 \%)$ \\
\hline \multicolumn{2}{|l|}{ Age group } \\
\hline $16-20$ & $55(18.4 \%)$ \\
\hline $21-30$ & $134(44.8 \%)$ \\
\hline $31-40$ & $68(22.7 \%)$ \\
\hline $31-40$ & $40(13.4 \%)$ \\
\hline $41-50$ & $1(0.3 \%)$ \\
\hline \multicolumn{2}{|l|}{ Schooling } \\
\hline Complete primary education & $22(7.4 \%)$ \\
\hline Complete high School & $39(13.0 \%)$ \\
\hline Incomplete higher education & $75(25.1 \%)$ \\
\hline Complete higher Education & $65(21.7 \%)$ \\
\hline Postgraduate Lato Sensu & $64(21.4 \%)$ \\
\hline Postgraduate Stricto Sensu & $31(10.4 \%)$ \\
\hline \multicolumn{2}{|l|}{ Socioeconomic level } \\
\hline $\mathrm{D}$ & $1(0.3 \%)$ \\
\hline $\mathrm{C}$ & $24(8 \%)$ \\
\hline B & $93(31.1 \%)$ \\
\hline A & $162(54.1 \%)$ \\
\hline
\end{tabular}

Values express absolute and relative frequency. 


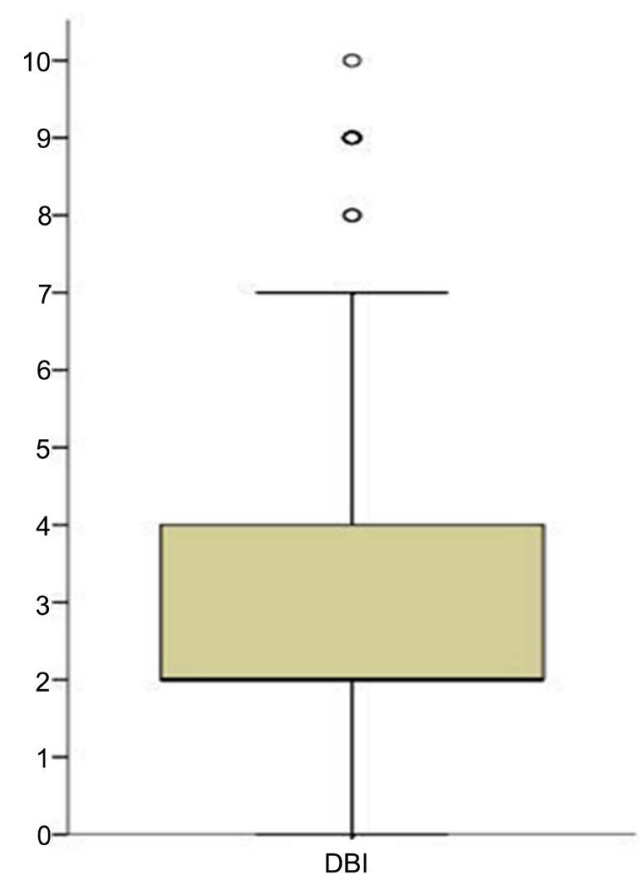

Figure 2. Body image dissatisfaction among study participants. BID: Body image dissatisfaction.

Regarding the associations of BID and age and social relations, the analysis showed that were statistically similar $(\mathrm{F}=0.81, p=0.517$ and $\mathrm{F}=1.37, p=0.244$, respectively). The BID and social relations also did not differ significantly between subjects who practiced physical activity until 90 minutes, from 90 to 120 minutes and more than 120 minutes $(\mathrm{F}=1.20, p=0.304$ and $\mathrm{F}=2.40, p=0.092$, respectively).

There was a statistically significant positive correlation between BMI and BID $\left(r_{s}=0.29, p<0.001\right)$. It was found that, for each increase in one unit in the BMI, the BID varied in 0.3 point (with a mean of 0.69), being lower among men than among the women, after adjusting for BMI.

The men had significantly higher BMI than the women (25.3 \pm 2.7 vs $22.3 \pm$ $3.0, \mathrm{~F}=67.46, p<0.001)$. As for BID, the mean score among men was significantly higher than among women ( $3.7 \pm 1.8$ vs $2.2 \pm 1.7, p<0.001)$.

In relation to the association between BID and goals for the practice of physical activity, it was found that the proportion of women who practiced physical activity with aesthetic goals was higher than that of men (69.2\% versus $30.8 \%, P$ $=0.07$ ), as described in Table 2. However, there was no association between gender and health or social relation objectives as a reason for performing physical activity ( $p=0.212$ and 0.753 , respectively). There was also no difference in the age distribution among those who had health or didn't as a target for physical activity $(p=0.199)$, aesthetic $(p=0.162)$ and social relation $(p=0.990)$. Likewise, there was no statistically significant difference in BID among those who had or not health as objective to perform physical activity $(p=0.412)$, aesthetic $(p=0.377)$ and social relation $(p=0.321)$. 
Table 2. Association between goals for the practice of physical activity, gender, age group and BID.

\begin{tabular}{|c|c|c|c|}
\hline & \multicolumn{3}{|c|}{ Objective for the practice of physical activity } \\
\hline & $\begin{array}{l}\text { Health } \\
(\mathrm{n}=231)\end{array}$ & $\begin{array}{l}\text { Aesthetic } \\
(\mathrm{n}=159)\end{array}$ & $\begin{array}{c}\text { Social relationships } \\
\qquad(\mathrm{n}=18)\end{array}$ \\
\hline \multicolumn{4}{|c|}{ Gender } \\
\hline Male & $93(40.3 \%)$ & $49(30.8 \%)$ & $8(44.4 \%)$ \\
\hline Female & $138(59.7 \%)$ & $110(69.2 \%)$ & $10(55.6 \%)$ \\
\hline \multicolumn{4}{|c|}{ Age group } \\
\hline $16-20$ & $39(16.9 \%)$ & $32(20.1 \%)$ & $3(16.7 \%)$ \\
\hline $21-30$ & $99(42.9 \%)$ & $78(49.1 \%)$ & $8(44.4 \%)$ \\
\hline $31-40$ & $58(25.1 \%)$ & $31(19.5 \%)$ & $4(22.2 \%)$ \\
\hline $31-40$ & $34(14.7 \%)$ & $18(11.3 \%)$ & $3(16.7 \%)$ \\
\hline $41-50$ & $1(0.43 \%)$ & 0 & 0 \\
\hline BID & $2.9 \pm 2.0$ & $2.9 \pm 2.2$ & $3.4 \pm 2.5$ \\
\hline
\end{tabular}

BID: Body image dissatisfaction. Values express absolute and relative frequency or mean \pm standard deviation.

\section{Discussion}

In the present sample, which the most prevalent category was 21 to 30 years old, the percentile of BID was $92 \%$. Evidences from international research indicate that this prevalence has increased over the years.

The study by Markey \& Markey [5] show that, as BMI increases BID decreases, to indicate that there is a significant, negative and weak correlation between BMI and satisfaction with BI. According to Alvarenga et al. [1], the BID is not related to weight, since even eutrophic ones wished to be smaller, considering that, of the $64.4 \%$ of female Brazilian university students wished to be lower in some degree, $70.6 \%$ were eutrophic. In this study, on the other hand, a statistically significant correlation was observed between BMI and BID. From our experience with populations of fitness centers, we observed that BMI is higher by the amount of muscle mass in relation to the sedentary population, but BMI is the most commonly used measure in epidemiological studies for the classification of nutritional status and recommended weight indication.

In this study, women were more dissatisfied than men with their body image, even after controlling for BMI. Tessmer et al. [6] confirm that women present greater risks for the BID as BMI increases or changes more frequently when compared to men.

According to Costa et al. [7], Shih \& Kubo [8] and Smith [9] body dissatisfaction and concern about weight were often verified behaviors among women, while men want to be more muscular, they point out. The findings of Silva \& Saenger [10], in a study with 230 students of physical education, showed that $62.8 \%$ of men and $67 \%$ of women presented dissatisfaction with their BI, and the female gender was more dissatisfied by being overweight and the male by thin- 
ness.

According Bosi et al. [11], men were dissatisfied by thinness and women were overweight, corroborating our study. This dissatisfaction is observed in healthy individuals from different strata of the population. It should be noted that the silhouette scale used in this study to represent the BI in two-dimensional forms has limitations, which can cause failures in the total representation of the body and in the distribution of body fat, affecting the individual formation of BI and also the identification of CS, because the instrument is subjective and simple, and may have failed to evaluate complex aspects, such as the influence of family, friends, relatives and the media, which are known to be intervening variables in the process of $\mathrm{BI}$.

In this aspect, the literature shows that many women perceive themselves as obese, without their BMI falling into this classification. McGee et al. [12] found that $50 \%$ of young women considered to be underweight, based on BMI, are judged to be overweight. In this aspect, Kakeshita \& Almeida [13] in their study with university students, older than 18 years old, concluded that eutrophic or overweight women (87\%) over estimated their body size, whereas obese women and men $(73 \%)$, regardless of BMI, underestimated body size. Significant differences were found regarding gender, as well as general dissatisfaction with perceived BI, leading to the conclusion that men and women present BI distortion, underestimating or overestimating it. The results suggest BID, as they desire leaner bodies.

However, BID usually leads people to start a physical activity program, Oliveira [14] emphasizes, since a well-planned exercise routine can reduce body weight and make them reach bodies that they idealize. In this line, Russel [15] states that some studies have shown that women who practice physical activity have a more positive perception of their body.

As result, Zequinão et al. [16] suggest that physical exercise and participation in sports directly influence global self-esteem, improving physical competence and body self-esteem. In a study by Simões et al. [17], among the several reasons for the practice of bodybuilding, the most frequent were "aesthetics", "health" and "physical fitness". Similarly, according to Monteiro et al. [18], in the positive influence on the search for physical activities of the fitness center, we can report the aesthetic question, especially among women.

In this study, the main reasons for practicing physical activity in both genders were health, followed by aesthetics, more motivating for women, and finally the social factor.

For Damasceno et al. [19], the main motivation of the physical activity practice is also based on aesthetic factors.

Telles \& Moreira [20] evaluated 100 students in the age group between 16 and 25 years old, who should respond if they practiced physical activity regularly and indicate, among seventeen options, what motivated them to exercise. And the option that was most often marked as the main reason for practicing physical activity was aesthetics with $19.3 \%$, equivalent to 12 times, which also appeared 
among other options 18 times (29\%). The reasons that were in second and third place were to improve physical fitness and to be an athlete, which appear with 10 and 9 markings, respectively.

For Tahara, Schwartz \& Silva [21], the reasons that led the subjects to join the practice of physical activities in fitness centers focus on aesthetic issues (26.67\%), as well as on the expectation of improving quality of life (23.33\%). As to the maintenance of this program, what motivates the subjects to remain active is mainly the concern of the people in relation to the corporal aesthetics $(33.33 \%)$, as well as the search for the improvement of the quality of life (20\%).

In the study by Lopes \& Chiapeta [22], the group with ages ranging from 11 to 29 years old was motivated to practice physical activity for aesthetic factors and improvement of quality of life, whereas the population aged between 30 and 60 years old had the greatest concern the pursuit of quality of life at the expense of aesthetic standards. Gonçalves et al. [23] also concluded that the reasons for adherence to physical activities between middle and senior citizens are related to health of body and mind, as well as physical conditioning.

But, for Balbinotti \& Capozzoli [24], in a group of people from 21 to 40 years old, the most important reasons for the practice of physical activity were health, pleasure, stress control and aesthetics. The authors found out that the health reason had a higher score according to the increase in age, while the motive of competitiveness decreased. In this sense, Santos and Knijnik [25] analyzed that the reasons for adherence of adult individuals of both genders were leisure/quality of life (44\%), medical orientation (34\%) and aesthetics (11\%). So, according to these studies, with the increase of age, people are motivated to practice physical activity for the health and not for aesthetic factor.

A different result was obtained by Siqueira [26], whose sample was composed by Physical Education teachers from fitness centers in a city in the state of Tocantins, which reported that their students first seek gymnastics for aesthetic factors and then, related to health. It is assumed that this result is justified by the sample of young people. Rocha [27], in a population of adolescents to the third age, observed that the men had a greater incidence by the esthetic question than the women. In their research, Silva et al. [10] found out that men sought gyms for physical preparation and pleasure for exercise, and women for weight and pleasure provided by exercise.

In general, one of the factors that may explain the high interest in reducing body weight, especially by the female audience, is the media, which imposes anorexic standard of body aesthetics, motivating women with less age, a group considered as more suggestible, to adopt such behavior [21].

The physical fitness motive still presented a negative but not significant correlation with $\mathrm{BMI}, \% \mathrm{G}$ and $\mathrm{BID}$, suggesting a possible inverse relation. However, the weight control motive in the multivariate analysis was not associated with BID. However, it showed a greater effect in the model that used the $\% \mathrm{G}(\mathrm{F}=$ 8.26) than with the BMI $(F=6.09)$, suggesting that the amount of body fat exerts 
a greater influence on the reason for loss/weight control than the BMI. Perhaps because BMI does not discriminate the effects of overweight from muscle mass and fat, so individuals with similar values may have different clinical representations.

In this study, the social relation objective was not significantly associated with BID. On this, Bastos et al. [28] concluded that men and young adults are more motivated by social issues as people with higher education because of health and physical fitness. Although this research was composed by the majority of young people, $46.8 \%$ of the participants had completed a full course, which may justify this result.

Although we have found little research with the objective of identifying the reasons for the practice of physical activity and to analyze its relation with BI in adults attending fitness center, it seems that most of the reported studies points as the main reason for the search of the practice of physical is aesthetic activity, which is closely related to the search for the change of the current body image.

The findings of this study indicate that $92 \%$ of the studied sample showed BID, women are more dissatisfied than men with their BI and that men aim a more muscular body and women a slimmer one.

Regarding the association between BID and goals for the practice of physical activity, no statistically significant difference was observed among those who practiced physical activity with health, aesthetic or social relations goals.

This panorama is worrisome, leading us to reflect on strategies that aim to increase corporal acceptance, considering that the observed trend can be considered an epidemic.

\section{Declaration of Conflict of Interest}

The authors declare that there isn't conflict of interest.

\section{References}

[1] Alvarenga, M.S., Philippi, S.T., Lourenço, B.H., et al. (2010) Dissatisfaction with Body Image in Brazilian University Students. Jornal Brasileiro de Psiquiatria, 59, 44-51. https://doi.org/10.1590/S0047-20852010000100007

[2] Damasceno, V., Vianna, V.R.A., Vianna, J.M., Lacio, M., Lima, J.R.P. and Novaes, J.S. (2006) Body Image and Ideal Body. Brazilian Journal of Kinanthropometry and Human Performance, 14, 87-96.

[3] McPherson, K.E. and Turnbull, J.D. (2005) Body Image Satisfaction in Scottish Man and Implications for Promoting Health Behaviors. International Journal of Mens Health, 4, 3-12. https://doi.org/10.3149/jmh.0401.3

[4] Santos, J.F.S., Oliveira, P., Campos, A.A., Pereira, E.O. and Sousa, E.A. (2014) Relationship between Body Dissatisfaction and Physical Activity in Adolescents from the Urban Area of Irati-PR. Journal of Physical Education/UEM, 25, 193-201.

[5] Markey, C. and Markey, P. (2005) Relations between Body Image and Dieting Behaviors: An Examination of Gender Differences. Sex Roles, 53, 519-530. https://doi.org/10.1007/s11199-005-7139-3

[6] Tessmer, C.S., Silva, M.C., Pinho, M.N., Gazalle, F.K. and Fassa, A.G. (2006) Body 
Dissatisfaction in Gym Goers. Brazilian Journal of Science and Movement, 14, 7-12.

[7] Costa, S., Guidoto, E., Camargo, T.D., Uzunian, L. and Viebig, R. (2007) Disorders of Body Image and Eating Disorders in Athletes and Physical Activity Practitioners. Reading, Physical Education and Sports, Digital Magazine, 12, 114.

[8] Shih, M.Y. and Kubo, C. (2005) Body Shape Preference and Body Satisfaction of Taiwanese and Japanese Female College Students. Psychiatry Research, 133, 263-271. https://doi.org/10.1016/j.psychres.2004.10.008

[9] Smith, C. (2004) Women, Weight, and Body Image. In: Chrisler, J., Golden, C. and Rozee, P., Eds., Lectures on the Psychology of Women, McGraw-Hills, New York, 76-93.

[10] Silva, T.R. and Saenger, G. (2011) Factors Associated with Body Image in Physical Education Students. Motriz: Revista de Educação Física, 17, 630-639. https://doi.org/10.1590/S1980-65742011000400007

[11] Bosi, M.L.M., Luiz, R.R., Uchimura, K.Y. and Oliveira F.P. (2008) Eating Behavior and Body Image among Physical Education Students. Jornal Brasileiro de Psiquiatria, 57, 28-33. https://doi.org/10.1590/S0047-20852008000100006

[12] McGee, B.J., Hewitt, P.L., Shery, S.B., et al. (2005) Perfectionist Self-Presentation, Body Image and Disorders Symptoms. Body Image, 2, 29-40. https://doi.org/10.1016/j.bodyim.2005.01.002

[13] Kakeshita, I.S. and Almeida, S.S. (2006) Relationship between Body Mass Index and the Perception of Self-Image in University Students. Revista de Saúde Pública, 40, No. 3.

[14] Oliveira, R.J. (2005) Health and Physical Activity: Some Approaches on Physical Activity Related to Health. Shape, Rio de Janeiro.

[15] Russel, K. (2004) On Versus off the Pitch: The Transiency of Body Satisfaction among Female Rugby Players Cricketers and Netballers. Sex Roles, 51, 561-574. https://doi.org/10.1007/s11199-004-5466-4

[16] Zequinão, M.A., Felizola, F.L.V., Ceola, E.P.A. and Matos, P.H. (2011) Perception and Body Satisfaction in Relation to Physical Exercise. Brazilian Journal of Physical Activity \& Health, 16, 95-99.

[17] Simões, C.S.M., Samulski, D.M., Simim, M. and Santiago, M.L.M. (2011) Analysis of the Quality of Life of Teachers and Students of Bodybuilding: A Comparative Study. Brazilian Journal of Physical Activity \& Health, 16, 107-112.

[18] Monteiro, C.A., Conde, W.L., Matsudo, S.M., et al. (2003) A Descriptive Epidemiology of Leisure-Time Physical Activity in Brazil, 1996-1997. Pan American Journal of Public Health, 4, 246-254. https://doi.org/10.1590/S1020-49892003000900005

[19] Damasceno, V.O., Lima, J.R.P., Vianna, J.M., Vianna, V.R.A. and Novaes, J.S. (2005) Ideal Physical Type for Hikers. The Revista Brasileira de Medicina do Esporte, 11, 181-186. https://doi.org/10.1590/S1517-86922005000300006

[20] Telles, S. and Moreira, E.H. (2006) School Physical Education in the Adoption of an Active Lifestyle. Fluminense Meeting of Physical School Education. Leisure and Physical School Education. Niterói.

[21] Tahara, A.K., Schwartz, G.M. and Silva, K.A. (2003) Adherence and Maintenance of the Practice of Exercises in Fitness Centers. Revista Brasileira de Ciência e Movimento, 11, 7-12.

[22] Lopes, V.M.B.S. and Chiapeta, S.M.S.V. (2010) Reasons for Adherence and Maintenance of Regular Physical Activity in Fitness Centers in the City of Ubá, MG. 
[23] Gonçalves, A.K., Duarte, C.P. and Santos, C.L. (2007) Physical Activity in the Middle-Age Stage: Reasons for Adherence and Continuity.

[24] Balbinotti, M.A.A. and Capozzoli, C.J. (2008) Motivation to the Regular Practice of Physical Activity: An Exploratory Study with Practitioners in Gymnastics. Revista Brasileira de Educação Física, 22, 63-80.

[25] Santos, S.C. and Knijnik, J.D. (2006) Reasons for Adherence to Physical Activity in Middle Adult Life I. Mackenzie Journal of Physical Education and Sport, 5, 23-34.

[26] Siqueira, F. (2009) The Focus Focused on Activities Developed in the Academies of Araguaína. Sports and Recreation.

[27] Rocha, K.F. (2008) Reasons for Joining the Gymnastics Practice. Journal of Sport and Health, 4, 11-16.

[28] Bastos, J.L.D. and Duquia, R.P. (2007) One of the Most Used Guidelines in Epidemiology: A Cross-Sectional Study. Scientia Medica, 17, 229-232. 